\title{
APLICAÇÃO DE ADSORVENTE ALTERNATIVO PARA PURIFICAÇÃO DE UM RESÍDUO DE GLICERINA.
}

\author{
N.R. Uliana ${ }^{1}$, M.B. Quadri ${ }^{1}$, R.A.F. Machado ${ }^{1}$, J.V. Oliveira $^{1}$ \\ ${ }^{1}$ Universidade Federal de Santa Catarina, Departamento de Engenharia Química, SC, Brasil. \\ Email para contato: nilvauli@yahoo.com.br, mbq1959@hotmail.com
}

\begin{abstract}
RESUMO: Uma das formas de purificar um resíduo de glicerina é através do uso de processos adsortivos, onde neste caso, a escolha do adsorvente é determinante. Neste trabalho, estudou-se a aplicação da argila bentonita fixada na forma de pó sobre a superfície de pellets de polietileno de alta densidade (PEAD) como adsorvente para a purificação de um resíduo de glicerina com acidez inicial de $0,84 \mathrm{mgKOH} / \mathrm{g}$. Pellets com argila foram produzidos utilizando um rotaevaporador com controle de temperatura e agitação. Posteriormente, preparou-se uma solução do resíduo de glicerina em água destilada para a realização de ensaios de adsorção em batelada com os pellets recobertos com argila. Nos testes preliminares do tratamento da acidez por adsorção, o índice final foi de $0,29 \mathrm{mgKOH} / \mathrm{g}$ de argila do resíduo de glicerina diluída e $0,478 \mathrm{mgKOH} / \mathrm{g}$ de argila do resíduo de glicerina sem diluição, tendo-se chegado ao equilíbrio depois de 24 horas a temperatura ambiente. Esse valor é aceitável de acordo com a norma NBR 14448.
\end{abstract}

Palavras-chave: adsorção, glicerina, índice de acidez, bentonita, polietileno.

\section{INTRODUÇÃO}

O glicerol ou glicerina bruta é o principal subproduto resultante do processo de fabricação do biodiesel, é de extrema importância uma vez que cerca de 10\% do volume de matéria-prima (óleo ou gordura) adicionada, inicialmente, ao processo produtivo é convertida em glicerina. (DASARI et al., 2005). Devido a isso, torna-se necessária a busca de alternativas para o uso do glicerol gerado nesta produção, com o intuito de evitar futuros problemas derivados do acúmulo de glicerol e para tornar a produção de biodiesel mais competitiva (OOI et al.,2004).

O grande obstáculo da utilização deste composto é a sua pureza, porque após a reação de transesterificação alguns resíduos do processo acabam misturados à glicerina, por conseguinte o produto obtido na verdade consiste de uma mistura de glicerol, álcool (metanol ou etanol), água, sais inorgânicos proveniente dos catalisadores (hidróxido de potássio ou sódio), mono, di e 


\section{9 a 22 de outubro de 2014 \\ Florianópolis/SC}

triglicerídeos que não reagiram completamente, ácidos graxos livres, ésteres metílicos e etílicos e outras substâncias que podem ser encontradas dependendo da natureza do óleo e da maneira com que o procedimento foi efetuado (CHUN-HUI et. al., 2008).

Nas diversas aplicações da glicerina como em remédios, alimentos, resinas alquídicas, polióis e explosivos, a pureza é de fundamental importância nos processos de síntese destes derivados, requerendo-se preferencialmente teores entre 80 a $95 \%$ e, em torno 99,5\%, no caso da chamada glicerina técnica e na aplicada na indústria farmacêutica (SALVADOR; MACHADO; SANTOS, 2006). São necessários processos complexos e onerosos para que essa matéria-prima alcance o grau de pureza exigido pelo mercado, considerando, ainda, que a tecnologia exigida para a sua purificação tem custo elevado (ROBRA, ALMEIDA NETO e CRUZ, 2006).

Assim, a possibilidade de conversão da glicerina nos mais variados derivados depende da sua purificação e do custo da mesma. Conforme Chun-Hui et al., (2008), "a purificação do glicerol é uma chave econômica e tecnológica de interesse no processo industrial do biodiesel".

Vários tipos de glicerina estão disponíveis comercialmente e diferem um pouco em seu conteúdo de glicerol e em outras características como cor, odor e teor de impurezas (KNOTHE et al., 2006). Uma glicerina purificada permite a síntese de uma variedade de compostos, desde os produtos das indústrias farmacêuticas e de cosméticos, até possíveis futuras utilizações como aditivos, resinas e pesticidas (FERREIRA, 2009).

Dentre as principais técnicas de purificação e tratamento, usando a glicerina que estão sendo investigadas destacam-se, método convencional, de troca iônica e carvão ativado. Ambos envolvem operações unitárias (evaporação e destilação) e processos unitários (acidificação e neutralização), com grande consumo energético, perdas de tempo e baixo rendimento.

A adsorção é uma operação de separação na qual se utiliza a habilidade de alguns sólidos se acumularem, em suas superfícies, substancias presentes em uma fase fluida (liquida ou gasosa). Os principais termos geralmente utilizados nos processos de adsorção são: (1) adsorvente é o material sólido empregado para a separação de uma ou mais substancias na fase fluida. (2) adsorvato que são as substancias a serem adsorvidas (DABROWSKI, 2001). Na adsorção existem vários fatores importantes. A estrutura molecular ou a natureza do adsorvente é determinante no ordenamento e grau de adsorção que pode ocorrer.

Adsorventes comerciais são divididos em quatro classes principais: zeólitas, alumina ativada, sílica gel e carvão ativado. Dentre estes, o carvão ativado é o mais comumente utilizado. Vários materiais diferentes e de baixo custo têm sido estudados para o uso como adsorventes nas mais diversas aplicações, tais como madeira, casca de laranja, argilas, sílica, quitosana etc. (NAMASIVAYAM e KAVITHA, 2002), devido às suas vantagens econômicas.

Devido a esses fatores, tem crescido o interesse por parte dos pesquisadores em estudar a técnica de adsorção usando adsorventes alternativos e de baixo custo, pois está técnica elimina algumas etapas do processo diminuindo custos e agregando valor ao produto. Neste trabalho, 
estudou-se a aplicação da argila bentonita fixada na forma de pó sobre a superfície de pellets de polietileno de alta densidade (PEAD) como adsorvente para a purificação de um resíduo de glicerina. Nesse contexto, a busca por formas de tratamento da glicerina é de extrema importância, uma vez que garante o fluxo de produção de biocombustível e, ainda, oferece suporte destinando um subproduto ou coproduto da produção de biocombustíveis.

\section{EXPERIMENTAL}

\subsection{Materiais}

Foram utlizados para a preparação do adsorvente pellets de poliestireno de alta densidade (PEAD) e argila Bentonita fornecida pela empresa T-cota, essa argila é resultante de uma pesquisa de bentonitas em desenvolvimento para compostos de nutrição animal e compostos adsorventes de toxinas. Como adsorvatos foram usados Glicerol P.A. (Vetec), ácido graxo fornecido pela SGS Agricultura e Industria Ltda e um resíduo de glicerina fornecido pela OLFAR S/A - Alimento e Energia.

\subsection{Procedimento experimental}

Os experimentos em batelada foram conduzidos à temperatura ambiente, em Erlenmeyer de $100 \mathrm{~mL}$, aos quais foram adicionados uma determinada massa de adsorvente (argila/polietileno) e um volume de glicerol PA com concentração de ácido graxo de 3\% e 5\% tanto puro quanto diluído em água destilada na proporção de 1:4. Posteriormente foram realizados ensaios com resíduo de glicerina tanto puro quanto diluído seguindo o mesmo procedimento. $\mathrm{O}$ contato entre o adsorvente e o adsorvato foi realizado através de agitação com shaker agitador magnético. Os experimentos foram deixado em agitação por 24horas, retirando amostras do líquido sobrenadante para realização de análise do índice de acidez.

\subsection{Preparação dos adsorventes argila/polímero.}

A argila em pó e o polímero PEAD em pellets foram pesados na proporção de 1:1, colocados em um balão volumétrico de fundo redondo e com a utilização do equipamento rotaevaporador foi fixado à argila na superfície dos pellets de polímero (PEAD). Para atingir a temperatura de aquecimento da mistura argila-polímero no banho térmico foi utilizado óleo térmico com temperatura de aquecimento de aproximadamente $150^{\circ} \mathrm{C}$ e uma rotação de $85 \mathrm{rpm}$. Após o processo de fixação, os pellets foram peneirados em peneira de 14 malha mesh de abertura de 1,40mm para retirada do excesso de partículas de argila não aderidas ao polímero. 


\subsection{Determinação do índice de Acidez}

O índice de acidez baseado na norma EN14104 é dado pela massa de NaOH necessária para neutralizar os ácidos graxos livres, contidos em 2 gramas de amostra. A acidez corresponde à porcentagem de ácidos graxos livres de uma gordura ou óleo. $\mathrm{O}$ processo resume-se na neutralização por intermédio de uma solução $0,01 \mathrm{~mol} \mathrm{~L}^{-1}$ de $\mathrm{NaOH}$, dos ácidos graxos livres existentes em uma amostra de 2,0g de resíduo de glicerina dissolvido num solvente neutralizado constituído de uma solução $25 \mathrm{ml}$ de éter etílico/etanol. A titulação é efetuada até o ponto de viragem da solução de fenolftaleína (2 gotas), ou seja, até a detecção de uma cor rosada permanente da amostra. $\mathrm{O}$ índice de acidez expresso em $\mathrm{mg}$ de $\mathrm{KOH}$ por grama de amostra foi calculado segundo a equação:

$$
I A=\frac{56,1 \cdot V \cdot N}{m}
$$

Onde:

$\mathrm{IA}=$ índice de acidez em $\mathrm{mgKOH} / \mathrm{g}$

$\mathrm{V}=$ volume gasto na titulação

$\mathrm{N}=$ normalidade do $\mathrm{KOH}$

$\mathrm{m}=$ massa de amostra em gramas.

\section{RESULTADOS E DISCUSÕES}

Podemos observar na Figura 1 que o resultado da fixação da argila T-cota nos pellets de PEAD em relação aos pellets do polímero padrão (puro) foi satisfatória.

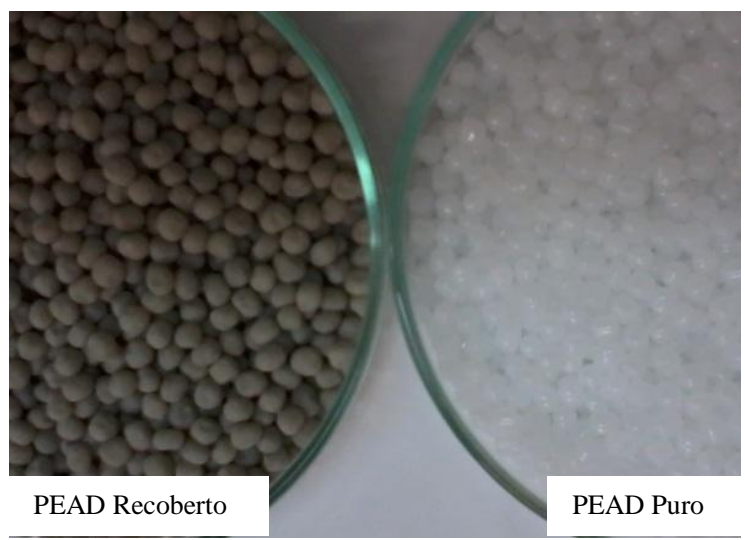

Figura 1 - Pellets de PEAD puro e pellets de PEAD recobertos com argila T-cota 
Nas Figuras a seguir são apresentadas as imagens obtidas por microscopia eletrônica de varredura (MEV) de pellets inteiros e cortados de PEAD sem recobrimento com argila (Figura 2), recobertos com argila antes de serem utilizados no processo de adsorção e após o uso na adsorção.
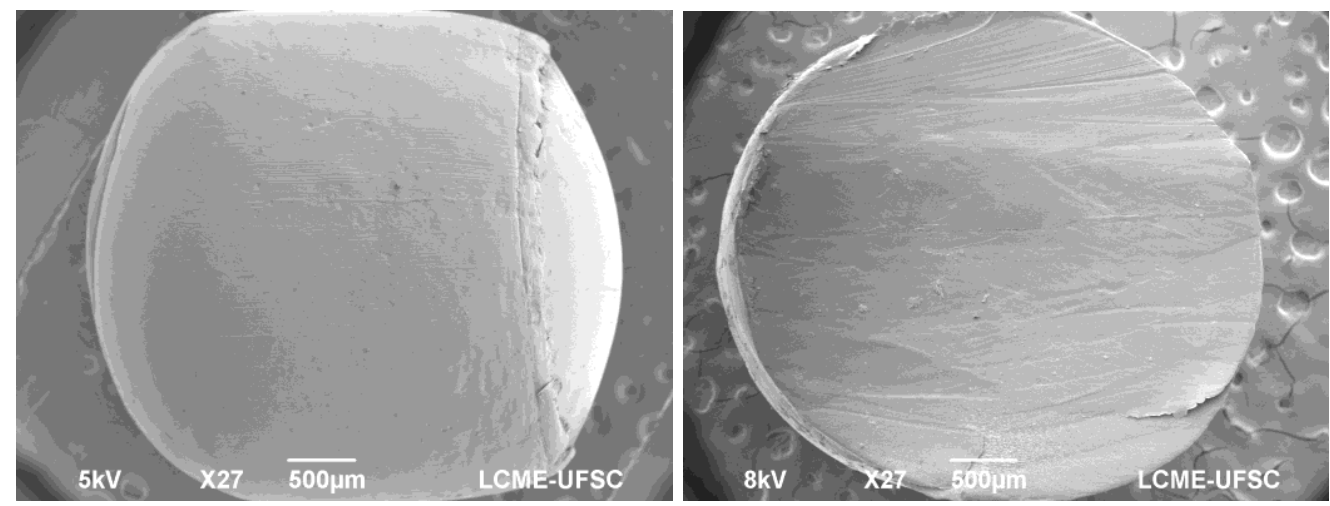

Figura 2 - Micrografia eletrônica de varredura de um pellet sem recobrimento com argila

Podemos observar nas Figuras 3 e 4 que a superfície externa do pellet de polietileno de alta densidade se encontra totalmente recoberta com uma camada de argila. Nos pellets cortados ou fraturados, o contorno corresponde a uma fina camada pouco visível de argila e a região interna à matriz polimérica. Pode-se observar que a superfície externa do pellet de PEAD apresenta irregularidades na sua superfície após o processo de aquecimento para a fixação da argila. Essas irregularidades podem ser decorrentes do movimento giratório do balão no rotaevaporador que provoca o impacto dos pellets de superfície amolecida com as partículas de argila.

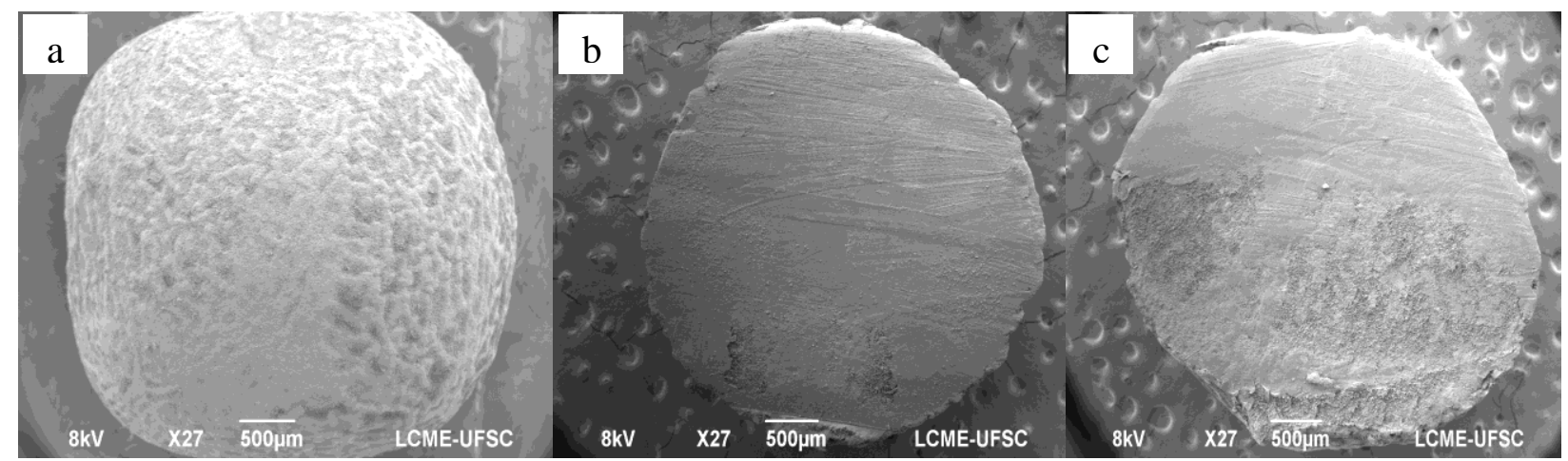

Figura 3 - Micrografias com aumento de 27 vezes: a) Pellet inteiro; b) Lado interno do pellet cortado; c) Lado externo do pellet cortado após o processo de adsorção 


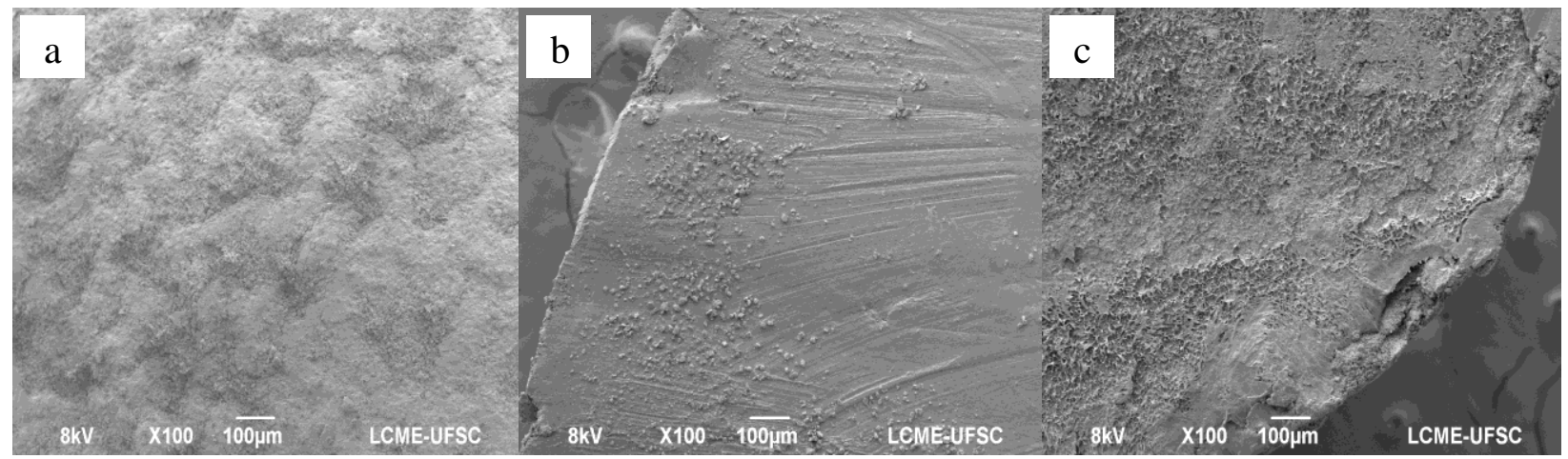

Figura 4 - Micrografias com aumento de 100 vezes: a) Pellet inteiro; b) Lado interno do pellet cortado; c) Lado externo do pellet cortado após o processo de adsorção

Nos ensaios de adsorção em batelada, com duração total de 24 horas, realizaram-se experimentos com diferentes teores iniciais de ácido graxo (3\% e 5\% em massa) em glicerina PA para verificar o comportamento do adsorvente com relação ao ácido graxo. Os testes foram conduzidos em duas modalidades: amostras preparadas com glicerol/ácido graxo, e amostras diluídas em água na proporção de 4 partes de água para 1 parte de glicerol/ácido graxo. A massa de adsorvente (pellet + argila aderida) utilizada foi de 1 parte para 4 partes de glicerol sendo que a aderência em grama de argila por grama de polímero foi de $0,22 \mathrm{~g}$, tendo uma incorporação de $0,55 \%$ a $0,59 \%$ de argila no adsorvente utilizado de acordo com as concentrações.

A Figura 5 apresenta a evolução da adsorção em função do tempo para os casos testados. Percebe-se uma redução acentuada do índice de acidez nos primeiros $150 \mathrm{~min}$ do processo, seguindo-se uma etapa transiente com alguma retomada de acidez que evolui lentamente por um período de 24 horas até uma condição razoavelmente estável, ou seja, o equilíbrio. A razão para esse comportamento ainda não está elucidada e é tema da pesquisa que ora se desenvolve.

Pode-se verificar pelos resultados apresentados na Tabela 1 e na Figura 5 que ouve uma redução significativa da acidez. As porcentagens iniciais relativamente elevadas de ácidos graxos nesses experimentos correspondem aos valores muitas vezes encontrados na fase glicerinosa obtida como subproduto na fabricação do biodiesel. O teor de ácidos graxos livres indica o grau de hidrolização das gorduras devido à ação da água, temperatura e/ou presença de enzimas. Mesmo com níveis elevados de acidez e pequena massa de adsorvente, obteve-se redução sensível no índice de acidez, atestando a efetividade desse tipo de argila na adsorção dos ácidos graxos presentes na glicerina.

Nos ensaios com o resíduo glicerinoso proveniente da indústria de biodiesel se deve ter em conta a composição mais complexa do material que possui umidade, cinzas, metanol, glicerol, matéria não glicerinosa e um alto teor de cloretos. Mesmo assim, segundo os dados da Tabela $1 \mathrm{e}$ Figura 5, comprovou-se uma vez mais o bom desempenho do adsorvente na redução do índice de acidez das amostras testadas. No final do processo de adsorção, o IA do resíduo diluído foi de 0,294 $\mathrm{mgKOH} / \mathrm{g}$ e o IA do resíduo não diluído foi de $0,478 \mathrm{mgKOH} / \mathrm{g}$, tendo-se partido de um 
resíduo de glicerina sem tratamento com $\mathrm{IA}=0,840 \mathrm{mgKOH} / \mathrm{g}$. Reduções importantes igualmente são observadas para os teores de ácidos graxos livres (AGL).

Tabela 1 - Resultados dos testes do índice de acidez e ácidos graxos livres ao final de 24 horas

\begin{tabular}{llllc}
\hline Amostra & $\begin{array}{l}\text { Acidez } \\
\text { inicial }\end{array}$ & $\begin{array}{l}\text { AGL } \\
\text { inicial }\end{array}$ & $\begin{array}{l}\text { Acidez } \\
\text { final }\end{array}$ & $\begin{array}{c}\text { AGL } \\
\text { final }\end{array}$ \\
\hline Glicerol/ácido graxo 3\% & 5,441 & 2,720 & 2,786 & 1,393 \\
Glicerol/ácido graxo 5\% & 4,865 & 4,650 & 3,481 & 1,741 \\
Glicerol/ácido graxo 3\% diluído & 2,659 & 1,330 & 0,982 & 0,491 \\
Glicerol/ácido graxo 5\% diluído & 4,463 & 2,231 & 1,119 & 0,560 \\
Resíduo glicerina & 0,840 & 0,420 & 0,478 & 0,239 \\
Resíduo glicerina diluído & 0,840 & 0,420 & 0,294 & 0,147 \\
\hline
\end{tabular}

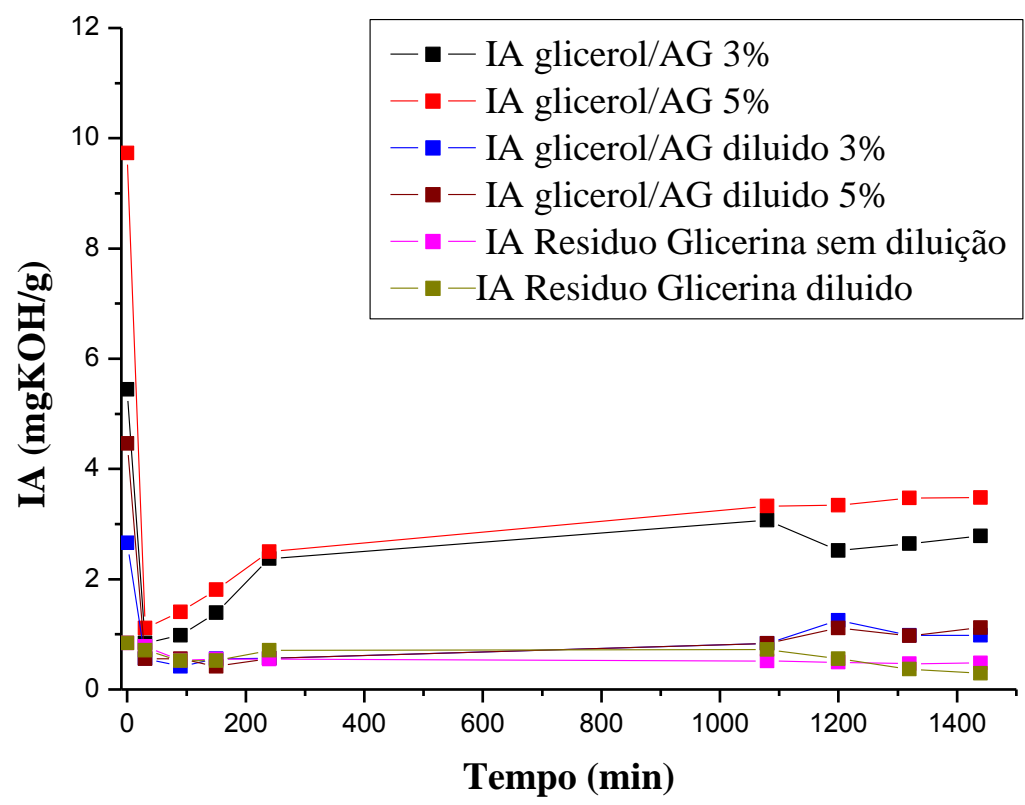

Figura 5 - Resultados do índice de acidez em função do tempo

\section{CONCLUSÕES}

Com os resultados obtidos nesse trabalho, pode-se verificar que o adsorvente utilizado para a redução da acidez de amostras de glicerina apresentou um bom desempenho. Ao se partir de um resíduo industrial com IA de $0,840 \mathrm{mgKOH} / \mathrm{g}$, obteve-se ao final do processo um IA de $0,478 \mathrm{mgKOH} / \mathrm{g}$; o resíduo diluído em água apresentou ao final um IA ainda mais baixo de 0,294 $\mathrm{mgKOH} / \mathrm{g}$. Sabe-se que mesmo com as impurezas próprias do processo industrial, a glicerina já 
se constitui em um subproduto rentável. No entanto, é possível agregar valor a essa glicerina por meio de sua purificação e assim alcançar valores de mercado muito mais favoráveis. É essencial que os produtos gerados a partir dos subprodutos (glicerina) possam se inserir no mercado consumidor com boa relação custo/benefício. O método de purificação apresentado no presente trabalho pode vir a se constituir em alternativa inovadora e economicamente rentável.

\section{REFERÊNCIAS}

CHUN-HUI, C. Z.; BELTRAMINI, J. N.; FAN, Y.X.; LU, M. G. Q.; Chemoselective Catalytic Conversion of Glycerol as a Biorenewable Source to Valuable Commodity Chemicals. Chemical Society Reviews, n. 37, p. 527-549. 2008

DABROWSKI, A. Adsorption - from theory to pratice. Advances in Colloid and Interface Science, v. 90, p. 135-224, 2001.

DASARI, M. A.; KIATSIMKUL, P. P.; SUTTERLIN, W. R.; SUPPES, G.J.; Low-pressure hydrogenolysis of glycerol to propylene glycol, Applied Catalysis A: General, v. 281, p. 225-231, 2005.

FERREIRA, M. O.; Purificação da glicerina bruta obtida a partir da transesterificação do óleo de algodão. Dissertação (Programa de Pós- Graduação em Engenharia Química) - Universidade Federal do Rio Grande do Norte,Natal, 2009

KNOTHE, G.; GERPEN, J. V.; KRAHL, J.; RAMOS, L.P. Manual de Biodiesel. São Paulo: Edgard Blücher Editora, 2006.

NAMASIVAYAM C; KAVITHA D. Removal of Congo Red from water by adsorption onto activated carbon prepared from coir pith, an agricultural solid waste. Dyes and Pigments, vol 54, ed 1, 2002, p 47-58.

OOI, T. L.; YONG, K. C.; HAZIMAH, A. H.; DZULKEFLY, K.; WAN-YUNUS, W. M. Z.; Glycerol Residue - A Rich Source of Glycerol and Medium Chain Fatty Acids. Journal of Oleo Science. v. 53, p. 29-33, 2004.

PERUCH M.G.B. Adsorption of textile dyes in aqueous solution on activated carbon and activated alumina. Dissertation (Master in Chemical Engineering) - Federal University of Santa Catarina, Florianópolis, SC, 1997.

ROBRA, S.; ALMEIDA NETO, J.A.; CRUZ, R.S. Usos alternativos para a glicerina resultante da produção de biodiesel: Compostagem. Anais I Congresso da Rede Brasileira de Tecnologia de Biodiesel, Brasília, 2006.

SALVADOR, A.F.; MACHADO, A. S.; SANTOS, E. P. Purificação da glicerina Bruta Vegetal. Rede Brasileira de Tecnologia do Biodisel. Brasília, 2006. 